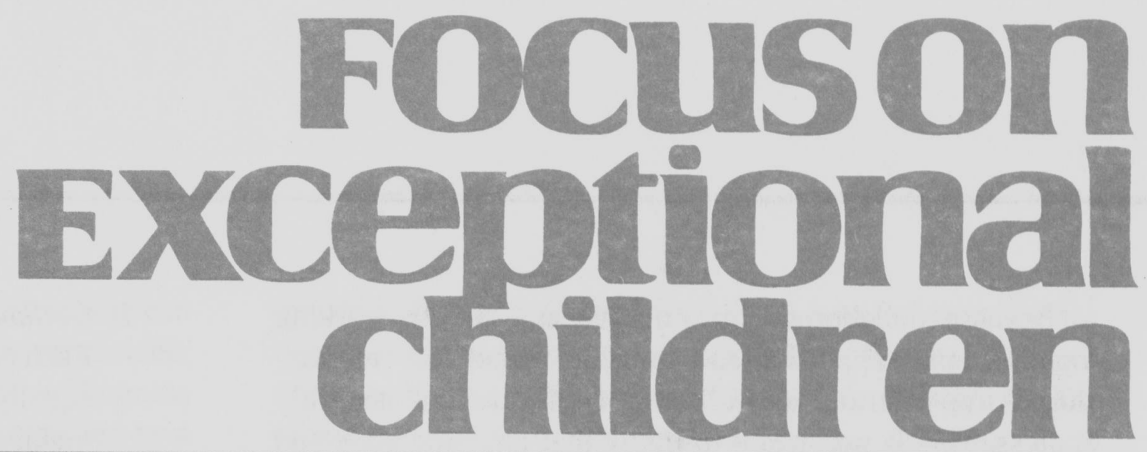

\title{
Collaborative Teaming in the Secondary School
}

\author{
by E. Ann Knackendoffel
}

Team or group approaches have long been a valued part of the special service professions and have become increasingly popular structures for addressing highly diverse issues in schools. The term collaborative teaming seems to embody this concept of working together. Knackendoffel, Robinson, Deshler, and Schumaker (1992) described collaborative teaming as an ongoing process whereby educators with different areas of expertise work together voluntarily to create solutions to problems that are impeding students' success, as well as to carefully monitor and refine those solutions. In short, the major goal of collaborative teaming is to improve services to students whose needs are not being met satisfactorily when professionals act alone rather than in concert with others.

The most productive collaborative relationships are characterized by mutual trust, respect, and open communication. Central to these relationships are the following beliefs:

1. All participants in the collaborative relationship must have equal status.

2. All educators can learn better ways to teach all students.

3. Educators should be involved continuously in creating and delivering instructional innovations.

4. Education improves when educators work together rather than in isolation. Effective collaborative relationships involve people who see themselves on the same side, working toward positive outcomes for students.

Collaborative teaming is a process rather than a specific service delivery model. For example, a general education teacher and a special education teacher may teach cooperatively in the same class setting with each taking on different instructional responsibilities depending on their individual strengths. In another teaming situation two teachers may get together regularly for cooperative planning purposes. In yet another scenario three special education teachers working in resource programs may team to coordinate group instruction and share students on their caseloads. In some schools, prereferral teams engage in collaborative teaming as they generate possible interventions for a student having difficulty in content classes.

E. Ann Knackendoffel is affiliated with Kansas State University. This article was adapted from Teaching Adolescents With Learning Disabilities, 2nd ed., published by Love Publishing Company, 1996. 
Because collaborative teaming means people working together in a supportive and mutually beneficial relationship, its possibilities and different configurations are truly endless. This is not meant to imply that anything goes and can be passed off as teaming. Friend and Cook (1992) lamented that collaboration has become the buzzword of the 1990 s and often is used carelessly to merely give the appearance of being in step with the latest educational innovations. The adolescents with whom we work are too important for us to simply go through the motions of collaboration to satisfy a school district's initiative or the latest educational trend. Friend and Cook (1992) identified what they refer to as defining characteristics of collaboration, which more fully explain what collaboration means. These are listed as follows:

1. Collaboration is voluntary. Education agencies can mandate administrative arrangements that require the staff to work in close proximity, but only the individuals involved can decide if their interactions will be truly collaborative.

\section{Focuson
Exceptional children}

ISSN 0015-511X FOCUS ON EXCEPTIONAL CHILDREN (USPS 203-360) is published monthly except June, July, and August as a service to teachers, special educators, curriculum specialists, administrators, and those concerned with the special education of exceptional children. This publication is annotated and indexed by the ERIC Clearinghouse on Handicapped and Gifted Children for publication in the monthly Current Index to Journals in Education (CIJE) and the quarterly index, Exceptional Children Education Resources (ECER). The full text of Focus on Exceptional Children is also available in the electronic versions of the Education Index. It is also available in microfilm from Serials Acquisitions, National Archive Publishing Company, P.O. Box 998, Ann Arbor, MI 48106-0998. Subscription rates: individual, \$42 per year; institutions, \$56 per year. Copyright (C) 2007, Love Publishing Company. All rights reserved. Reproduction in whole or part without written permission is prohibited. Printed in the United States of America. Periodical postage is paid at Denver, Colorado. POSTMASTER: Send address changes to:

Love Publishing Company

Executive and Editorial Office P.O. Box 22353

Denver, Colorado 80222

Telephone (303) 221-7333

\section{EDITORIAL BOARD}

$\begin{array}{cc}\begin{array}{c}\text { Lisa Dieker } \\ \text { University of Central Florida }\end{array} & \text { Paula Maccini } \\ \text { Mniversity of Maryland } & \text { Unersity of Wisconsin-Milwaukee } \\ \text { Univen } & \text { Stanley F. Love } \\ \text { Carrie E. Watterson } & \text { Publisher } \\ \text { Editor } & \end{array}$

2. Collaboration requires parity among participants. Each person's contribution to an interaction is valued equally, and each person has equal power in decision making. If one individual is perceived by others as having more power or more valuable knowledge or information, collaboration cannot occur.

3. Collaboration is based on mutual goals. To collaborate, professionals do not have to share many or all goals, just one that is specific and important enough to maintain their shared attention.

4. Collaboration depends on shared responsibility for participation and decision making. Equal participation in the decision making is important, but shared participation in task completion does not mean that tasks must be divided equally among involved individuals or that each must participate fully in all tasks. Participation in the activity often involves a convenient division of labor.

5. Individuals who collaborate share their resources. Each person engaged in a collaborative activity has resources to contribute that will be valuable for reaching the shared goal. The type of resources professionals have depends on their roles and the specific activity. Example resources include time and availability to carry out tasks, knowledge of a specialized technique, and access to other individuals or agencies that could assist in attaining the goal.

6. Individuals who collaborate share accountability for outcomes. Whether the results of collaboration are positive or negative, all the participating individuals are accountable for outcomes.

The term emergent characteristics of collaboration describes characteristics that must be present to some discernible degree at the outset of collaborative activity, and also emerge and grow when successful collaboration occurs. These are as follows:

1. Individuals who collaborate value this interpersonal style. Collaboration is difficult but rewarding. Individuals involved must believe that the results of their collaboration are likely to be more powerful and significant than the results of their individual efforts, or else they are unlikely to persevere. Typically, success leads to increased commitment to future collaboration.

2. Professionals who collaborate trust one another. Only after a period of time in which trust, and subsequently respect, are established can school professionals feel relatively secure in fully exploring collaborative relationships.

3. A sense of community evolves from collaboration. A sense of community is the perception that by inter- 
acting collaboratively, all participants' strengths can be maximized, their weaknesses can be minimized, and the result will be better for all. The willingness to work toward a common goal is accompanied by a decrease in concern about individual differences.

The benefits of collaboration do not come without risks. Collaboration is not accomplished easily, nor will teachers find it appropriate for every situation. Colleagues may not share one's enthusiasm. When collaborative efforts result in trusting relationships with colleagues and positive outcomes for students, however, the risks seem a small price to pay.

\section{COLLABORATIVE TEAMING READINESS}

If there is one obstacle to successful collaboration that will derail even the best developed plan, it is forcing collaboration between unwilling teachers. The decision to collaborate has to be made by the teachers who are involved and supported by the administration (Harris et al., 1987; Warner, 1990). The goal is always to move ahead in collaborative efforts. In your attempts to work with others, you will encounter various degrees of readiness to collaborate. Assessing where you are on the "relationship continuum" with the other person can help you choose realistic goals based on the colleague's level of readiness for collaborative teaming. In addition, this type of assessment can be useful in helping you determine how to best promote better relationships and move a colleague forward in your collaborative efforts.

If a relationship is nonexistent with the other party, the person may be hostile, indifferent, or apathetic, or this might be a person with whom no previous contact has existed. In any case the goal is to develop an amicable relationship with the person through social interaction or working together on committees or projects, sharing information or teaching ideas that might be of interest to the person. Lunching together or getting a cup of coffee after school provides other potential opportunities. This is not the time to push a specific agenda but, rather, to build a social relationship gradually with the person as a foundation for building a working relationship.

Sometimes only a social relationship exists with the other person (i.e., you might have social contact with the person but rarely engage in professional discussions). At this level the goal is to move into mutual discussion of work-related issues. For instance, when an opportunity arises, the colleague could be asked about some issue that the school board is debating or the colleague's opinion about the school's move to block scheduling could be solicited. The colleague might be asked about cooperative groupings or issues related to grading.

Often, what might be described as a "limited work rela- tionship" exists. This can involve two types of people. One type asks for assistance but doesn't follow through. The second type discusses problems when they are brought up but seems unwilling to participate in finding solutions. It is important to attempt to determine why the person will not accept suggested solutions. Does the person feel alienated by the other person's attitude or behavior? Does the solution itself involve something with which the person feels uncomfortable? Once the underlying problem in the relationship has been discovered, the task is to develop strategies that will remove the problems and allow for more productive collaboration. If this fails, the problem may have to be reassessed and new solutions developed that will satisfy the other person's concerns.

In some cases, you may find that the person is willing to work with you as long as you initiate the contact but does not seem to recognize when to ask for assistance. The task at this stage is to work with the teacher in recognizing and identifying problems suitable for collaboration so the person will initiate future contacts. The person might be given a form such as the one in Figure 1 to indicate when assistance is needed.

When you are working with a colleague who initiates contact, identifies problems, and helps to develop and implement solutions, think about how this person can assist in your efforts to develop better relationships with other teachers desired for the team but who may be at a lower level on the readiness scale. The teacher should be encouraged by being asked to work more closely with another staff member. This person's opinions should be solicited and respected.

Finally, after you have established a strong collaborative relationship with a colleague, you often find that the teacher not only seeks out assistance when needed but also becomes an active advocate of the teaming approach with other potential collaborative teachers. At this level the teacher believes strongly in your role, values your contribution, and is willing to help you expand to other settings. The collaborative relationship has become truly reciprocal.

Readiness to collaborate and team with one another is influenced by interactions. If a teacher is at a low level of readiness and is not progressing, the problem may reflect a lack of the other teacher's collaboration skills or may be the result of situational factors beyond the control of the other teacher. This may not be the other person's "fault." Some collaboration strategies are:

1. Treat others with respect. Demonstrate your respect for their ideas by really listening and letting them know they were heard.

2. Let others know that you appreciate their cooperation and value their expertise and knowledge.

3. Demonstrate through your actions that you deserve 


\section{ASSISTANCE NEEDED}

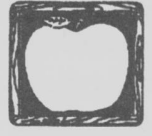

Today's Date

Teacher

Student

Other

There's a problem. Let's put our heads together.

I need your help in the classroom.

Develop alternative assignment or activity.

Arrange cooperative learning groups \& activities.

Implement peer tutoring or peer partners.

Produce alternative materials or locate resources.

Develop a modified grading system.

Create a study guide. $\square$ Plan a lesson.

Modify materials.

Team teaching.

Modify a test.

Classroom management.

Develop guided notes. $\square$ Instructional strategies.

When?

Additional information:

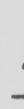

FIGURE 1 Assistance Request Form

their trust.

4. Acknowledge the realities of the teacher's situation (large number of students, limited time, diverse student abilities, etc.).

5. Deemphasize your contribution to the collaborative process - "onedownmanship" (West, Idol, \& Cannon, 1989).

6. Give others credit for their ideas and contributions.

7. Listen, listen, listen.

8. Use situational leadership; adjust your leadership style to the other person's needs (Idol, PaolucciWhitcomb, \& Nevin, 1986).

9. Use focusing statements to indicate that you not only have listened to your colleague's concerns but also are willing to incorporate them into the solution (Knackendoffel, Robinson, Deshler, \& Schumaker, 1992).

10. Communicate that the other teacher is free to accept or reject any recommendations.

\section{COLLABORATIVE PROBLEM SOLVING}

Nearly everything we do as learning disabilities specialists can be considered as some type of challenge or problem to be solved. At the heart of collaborative teaming is problem solving. Teachers engage in problem solving when they identify students, place them in programs, and decide on appropriate interventions. Teachers independently problem solve when they make decisions about scheduling or setting priorities in structuring a program. When the decision making is shared with others, problem solving becomes collaborative. Teachers engage in collaborative problem solving in team meetings and with individual colleagues to determine how to adapt instruction to meet students' needs.

Collaborative problem solving is fundamental to successful interactions with colleagues. And, though the steps to collaborative problem solving (Knackendoffel, Robinson, Deshler, \& Schumaker, 1992) presented here may seem straightforward, their complexity lies in their skillful implementation (Cummings, Murray, \& Martin, 1989). This involves a number of technical skills that are crucial to productive problem solving. The skills can be learned through practice. The relationship built with the other person determines, to a great extent, one's ability to problemsolve successfully.

Although the technical skills involved in problem solving are important, the way in which they are used and the tone and tenor of the meeting are equally important. A positive collaborative relationship must be developed across a series of problem-solving sessions. When a trusting or respectful relationship has been established using the partnershipbuilding skills discussed in this chapter, the problem-solving process will help colleagues jointly structure an effective solution-finding session.

Before engaging in a full-blown problem-solving process like the one described here, the teacher has to determine if the problem-solving process is necessary. Sometimes a colleague simply may need to talk about a situation. In these cases the teacher's main responsibility is to be a good listener. Friend and Cook (1992) suggested asking oneself the following questions to determine whether undertaking collaborative problem solving is warranted:

1. Are the individuals who have responsibility and resources for addressing the problem committed to 
resolving it?

2. What might happen if nothing is done to resolve the problem?

3. Does the problem warrant the effort and resources that will be required to effect significant change?

4. Are adequate time and resources available to resolve the problem?

In some cases the answers to these questions might steer the teacher away from the problem-solving process. Perhaps the problem is beyond the control of the people who are interested in addressing it. Maybe some preliminary work on strengthening the relationship has to take place before approaching the problem with a colleague. On the other hand, the teacher may decide that collaborative problem solving does seem appropriate for the situation and it would be time well spent. Teachers who find themselves helping someone solve a problem must recognize that their role is to assist in solving the problem, not to solve the problem. This means helping the person: understand the problem situation, generate alternative solutions, evaluate each alternative solution, select the best solutions for the problem, implement the solution, evaluate the outcomes, and make adjustments as needed. Solving the problem for the other person shifts the whole tenor of the situation away from collaborative teaming. Avoiding behaviors that the other person would interpret as directing or controlling is critical.

If the colleague senses that the teacher is overly dominating, two scenarios are possible: (a) the person is likely to avoid similar interactions in the future or (b) may become dependent on the other teacher. Neither of these outcomes is desirable when the overall goal is for two parties to be working in collaboration on behalf of a student.

The problem-solving process-described only briefly here - is detailed in the manual developed by Knackendoffel, Robinson, Deshler, and Schumaker (1992) entitled, Collaborative Problem Solving: A Step-by-Step Guide to Creating Educational Solutions. The steps outlined in this process should enable a teacher to avoid prescribing a solution while helping the colleague participate actively in the problemsolving process. These steps structure the problem-solving sessions and transform them from advice giving to collegial or collaborative solution-finding exchanges.

The Problem-Solving Worksheet in Figure 2 can be used to facilitate problem-solving sessions. It serves as a reminder of the problem-solving steps and provides a structured guide for taking notes during the session. The problem-solving process involves a series of 13 steps that will enable teachers to avoid prescribing a solution while helping colleagues participate actively in the problem-solving process.

Step 1: Define the problem. A clear definition of the prob- lem is critical to the remainder of the problem-solving process. Many people fail to arrive at effective solutions because they did not define the problem clearly. You want to arrive at one specific problem statement.

Step 2: Gather specific information about the problem. Gather as much information as possible to clarify the problem. Use active listening skills to get the other person to share information. The first two steps go hand-in-hand. You may need to gather information before coming up with a problem statement, or you may need to rewrite the problem statement after you have gathered additional information.

Step 3: Explain problem-solving process, and state its usefulness. Explain the process so your colleague has an overview of what is to follow. This may facilitate the process and prevent the potential problem of "shooting down" ideas during brainstorming, and thus stifling generation of further possible solutions (i.e., if your partner begins to tell you why a potential solution won't work during brainstorming phase of the process, you will be able to refer to the process that you agreed to follow and the importance of withholding judgment until all possible solutions are on the table for consideration).

Step 4: Identify alternative solutions. Use brainstorming to stimulate ideas. Finding a good solution is difficult and requires much thought. Initial solutions seldom are adequate. Begin by asking the other person for possible solutions. Offer your ideas in an open-ended fashion. All ideas should be treated with respect, and you should avoid negative or positive evaluation of any solution at this stage.

Step 5: Summarize solutions. When finished generating solutions, summarize all of the solutions you have written down and ask for any additional ideas before moving on.

Step 6: Analyze possible consequences. Go through the list of solutions one at a time, discussing possible consequences of each. Consider benefits, problems, practicality, time, and effort. Give each solution careful and serious consideration. Discuss possible consequences based on knowledge of best instructional practice. Don't write advantages and disadvantages on the Problem-Solving Worksheet. Just discuss them.

Step 7: Rate each solution. After analyzing consequences of all the solutions, review them one at a time, determine how satisfactory your colleague finds each solution, and express your satisfaction with each solution. Combine Steps 6 and 7 so the pros and cons of each solution are fresh in your minds during the rating process (i.e., discuss advantages and disadvantages of first solution and then immediately rate that solution before moving on to discussion of second solution).

Step 8: Select best solution. Make a mutual commitment to one solution. Give the list of rated solutions to your colleague and ask which is the best one based on the ratings 
PROBLEM-SOLVING WORKSHEET

Problem-solving team members:

Role:

Mark Wilson

Science Teacher

Linda Ryan

Student:

Jason Roberts, Camra Stevens \& Pete Hall English Teacher

Step \#1

Problem:

Jason, Camra and Pete are failing chapter tests.

They need information from the textbook.

Step \#2

Details:

Chapter test scores range from 40 to $50 \%$. Tests mainly factual; given every other week; most information comes from textbooks. Students need to get information from tests. Some time to read in class; some outside reading needed.

Step \#4

Alternative solutions:

1. Make study guides to go with chapters.

2. Have students study in pairs.

3. Tape record chapters.

4. Make special markings in selected textbooks.

5. Have students read parts of chapters and share main

ideas with other students.

6. Schedule after-school study sessions. Exc. Falr Poor

$\underline{x}-$

$-x-$

$-x-\frac{x}{x}$

$\underline{x}-$

$--$

$\underline{x}-$

Step \#8

Solution to be tried first:

Give students a study quide and have them share information.

Step \#1 I

Implementation steps:

When Who

1. Make up study guide for next chapter. Thurs., $10 / 22$ Mark

2. Make copies of study guide for all students. Fri., 10/23 Mark

3. Assign chapter reading to all students. Mon., 10/26 Mark

4. Have students hare information in class Linda/ at $10: 30$

5. Continue sharing activity throughout unit. Mark

6. Meet with Jason, Camra, \& Pete and have them set goals.

FIGURE 2 


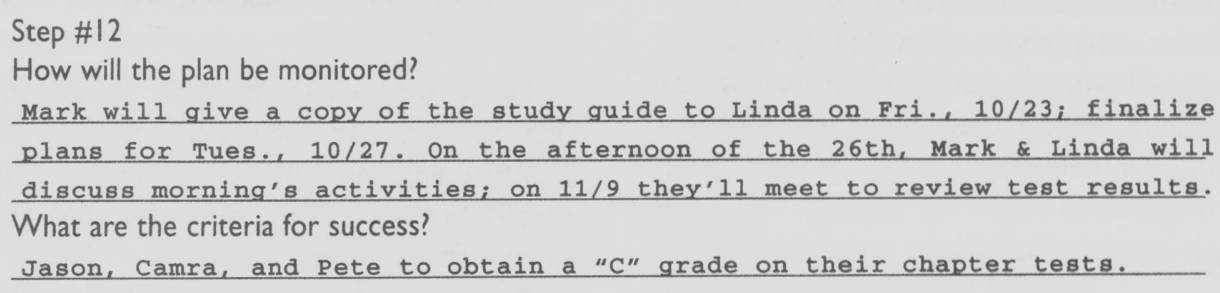

Step \#13

Date and Time of Next Appointment: Tues., $10 / 27$ and Mon., 11/9

\section{FIGURE 2 (Continued)}

and your discussion of pros and cons and best instructional practice. You may choose to combine two closely rated and compatible solutions.

Step 9: Determine satisfaction with chosen solution. After selecting a solution, ask your colleague if he or she is satisfied with the selection. Don't make the mistake of trying to push a solution through persuasion. If the solution is not chosen freely, chances are that it will not be carried out. If none of the solutions is satisfactory, go back to generating more solutions.

Step 10: State support for decision. Show your support of the chosen solution. Your colleague needs to feel not only that you accept his or her choice, but also that you will be there to help implement the solution.

Step 11: Develop plan of action. Jointly specify tasks required to implement the chosen solution. Indicate who will be responsible for completing each task and a time frame for completion. This process gives you a clear plan of action and eliminates later questions concerning who is responsible for each step. It encourages accountability.

Step 12: Develop monitoring system and specify criteria for success. Include dates on which progress checks will be made and what is expected to be completed by those dates. Simple monitoring systems that require minimal time work best. Specify the criteria for success to avoid later misunderstandings and to be sure that both parties share the same expectations.

Step 13: Schedule next appointment. Schedule a followup appointment and make a copy of the completed ProblemSolving Worksheet for your colleague. Along with encouraging action, follow-up sessions prevent the other person from feeling abandoned or alone in the struggle. The tone of the follow-up session should be one of reporting progress, encouragement, and fine-tuning the plan rather than checking-up on your colleague's progress.

Research on the collaborative problem-solving process
(Knackendoffel, 1989) indicated some general guidelines to ensure that the problem-solving process is effective. First, the problem-solving facilitator must insist on specificity. When confronted with a problem, people often make vague statements that do not specify what the student is doing that is inappropriate or what the student has to do to be successful in the setting where the problem is occurring.

The second guideline has to do with problem ownership. During field-testing of this process, LD teachers learning the process were quick to take ownership of problems. When discussing shared students with learning disabilities, the special education teacher seemed to feel responsible for solving any problems associated with that student. This does not foster collegial or collaborative management of the education of adolescents with learning disabilities.

The third guideline involves the brainstorming technique used in generating potential solutions. Both participants should refrain from immediately evaluating solutions as they are generated. Each solution is put on the table before evaluating its utility. For a number of reasons, this procedure is more effective than evaluating each solution as it is contributed. By making a list of potential solutions and evaluating them in relation to each other, personal attachments to and investments in certain solutions are minimized. This also eliminates problems that can arise when a person discounts every solution as it is mentioned by saying, "I don't think that will work" or "I've already tried that, and it doesn't work."

Finally, concrete plans are necessary. Often a solution is agreed upon, but without specific implementation and monitoring plans, it dies a quick death. Research on the change process shows clearly that people underestimate the amount of assistance and follow-up required to implement new ways of doing things (Fullan, 1982; Joyce, Bennett, \& Rolheiser-Bennett, 1990). Plans stipulating who will implement certain parts of the solutions, when tasks are to be completed, and when and how progress will be evaluated are 
helpful to ensure that the solution is carried out.

The problem-solving worksheet is provided in Figure 2. It shows how a completed problem-solving worksheet might look and highlights the problem-solving steps with the corresponding parts of the worksheet.

\section{PARTNERSHIP-BUILDING SKILLS}

Most teachers spent little, if any, time in teacher preparation classes learning how to work with other adults. Yet teachers in today's schools rarely work in isolation. Increasingly, collaboration skills will be called upon as part of the teacher's daily job function. Strong interpersonal communication skills are as important to special education teachers as is knowledge of remedial and compensatory techniques. Beyond basic communication skills in areas such as active listening and effective questioning techniques, more subtle partnership-building skills can influence the long-term relationship between two professionals.

To take a professional relationship beyond the superficial level that often develops between teachers in the same building requires a commitment to build a long-term, productive, problem-solving partnership with the colleague.

Reaching the goal of a productive partnership is predicated upon a few basic principles. First, in a professional partnership the partners view themselves as being professionally equal and treat each other as professional equals. They respect and acknowledge each other's talents, skills, and expertise, and they value what the other person can bring to the partnership in terms of knowledge, ideas, skills, and perspective. Finally, they take care to protect the partner's feelings of competence and self-esteem (Knackendoffel, Robinson, Deshler, \& Schumaker, 1992).

Partnership-building skills fall under two general categories: equality builders and solution builders. Equality builders are behaviors that enable the parties to be equals in their interactions. Special education teachers entering the domain of general education teachers easily fall into the role of an advice giver-or at least can be perceived that way. Offering advice is a natural reaction to a problem. Therefore, equality-building skills are particularly important during interactions that seem to invite advice giving. The goal is to give up a position of superiority. Instead, the special educator's statements should indicate that the colleague is an equal and has valued ideas and concerns. Examples are:

\footnotetext{
"I'm glad you mentioned that concern. I hadn't thought of it from that perspective."

"I really value this chance to work with you. I've seen that you put a great deal of care into what you do in the classroom."

"You're the expert on your subject and this group of students, so I trust you to know best."
}

\footnotetext{
"That must be a frustrating situation for you. I know it would be for me."
}

These statements convey the attitude of working together side-by-side. They also acknowledge the other teacher's expertise and show that the special educator can relate personally to what is being said while not using the situation as an opportunity to tell his or her own story.

Although some disagreement exists in almost any professional partnership, an accepting atmosphere can be established by avoiding criticizing, blaming, and disapproving statements and actions. Criticism only creates barriers between professionals and may ultimately sabotage a relationship. Sincere compliments and statements of appreciation also can facilitate partnership building. As a cautionary note, compliments sometimes create a feeling that the complimenting person is acting in a superior role or is trying to manipulate the person with false praise. Likewise, empathic statements, if used incorrectly, might be unproductive. For example, an empathic statement might be used as a lead to tell a story about one's own success in a similar situation. Some examples of what not to say are:

\footnotetext{
"I said from the beginning that I didn't think it would work."

"You know, you're one of the few people in this school who really know what teaching is all about."
"I know exactly how you feel. John Jones did something way to handle the situation. Let me tell you what I did..."
"I know you're really angry at Kyle, and that's the reason you're having trouble thinking of solutions. You can't let your anger take over your logic." like that in my class last year, and I came up with the perfect
}

Another set of partnership-building skills, solution builders, are needed when creating positive solutions with a colleague. Attempts to push a solution on the other person are likely to be rejected, either openly or surreptitiously, by the other party. Although the other party may state that the solution is acceptable, the opposite may be revealed in failure to carry through on responsibilities related to carrying out the solution. To arrive at mutually acceptable solutions, both partners must be convinced that the solution meets the needs of all parties involved. Personal investment in solutions and being right have no place in the collaborative problem-solving process.

Really listening to a colleague's concerns is important Those concerns then can be incorporated into the chosen solution. An example is, "You're concerned about the message other students will receive if Paul doesn't seem to have to do as much as the other students. Let's see if we can find a solution that involves treating all students in a way they perceive as fair." By listening carefully and thinking about what this colleague is saying, the special education teacher can search 
for areas of agreement and communicate those areas of common ground: "Having a solution that requires Kathy to take responsibility for her work is something I can really support."

Immediately disagreeing with a colleague's suggestion focuses the discussion on the points that separate the two. If the colleague hears some agreement, he or she will feel affirmed and will be more willing to listen to the other's concerns and ideas. The words of the person offering an idea should show willingness to examine the solution and, if necessary, to discard or adjust it: "Here's an idea for us to consider. You've said that Bill doesn't believe he can succeed. What about a solution that includes making Bill aware of his poor beliefs about himself as a learner?" Whatever solution is chosen, ideally it should include instructional practices based on established learning principles. A good solution is based on what we know about best practice with at-risk students.

Diverting the discussion is one of the most common ways to switch a conversation from a colleague's concerns to a topic of one's own choice. Even if done unintentionally, such responses can communicate noninterest in the colleague's concerns. Another unfortunate tactic that teachers may be tempted to use when they don't agree with a colleague's solution is logical argument. Attempting to convince the other person by citing facts or logic without considering the emotional factors involved or clearly understanding the other party's concerns likely will fail. A logical argument presented at the wrong time can make the colleague defend his or her position more strongly. Rather than convincing the other person, it creates resistance, provokes defensiveness, and elicits counterarguments and, thus, ultimately alienates the colleague.

Offering solutions to someone is a delicate matter. Solutions can be offered in ways that offend people. If the solution does not address the colleague's concerns adequately, he or she might feel that the other person was not truly listening. If the solution is offered in a way that indicates it is set in stone, the colleague may feel that the other person is acting in a superior role and not allowing any other say in the matter.

The partnership-building skills discussed here are not allinclusive. They cover a few of the skills that are most critical when working with a colleague. Effective use of partnership-building skills and avoidance of the barriers does not happen overnight. Through self-examination and evaluation after each collaborative interaction, however, special educators should be able to improve their collaboration skills.

\section{STRUCTURING COLLABORATIVE TEAMING ARRANGEMENTS}

There probably are as many ways to arrange collaborative teaming structures as there are teams of teachers. Successful teams, however, do share common elements and avoid certain traps that can defeat even the best of intentions. Here we offer some personal insights and examples that have worked for other collaborating teachers. These starter techniques provide a basis for designing a personal blueprint for successful teaming.

\section{Collaborative Consultation}

One service delivery approach known as collaborative consultation (Idol, Paolucci-Whitcomb, \& Nevin, 1986) involves providing the general education content teacher with multidisciplinary planning support in an effort to improve the quality of instruction for LD students in their content classes. This approach engages the special educator in cooperative planning with the content teacher but not directly in actual program implementation. The general education teacher maintains primary responsibility for the delivery of instruction. This might be the option of choice when:

- the class contains only a few students with LD

- targeted students can function relatively independently in the academic setting (because of the mild nature of their learning disability or success with previous intervention programs such as learning strategies)

- when general and special education teachers have been engaged in a cooperative teaching arrangement for some time and think they are ready to phase out the direct service delivery program option

- the special educator has limited time compounded by a large caseload

Many special educators believe that collaboration means being in the classroom where the LD students are placed and being involved in cooperative teaching. Certainly this is one option, but it is not feasible, or even necessary in all situations. Teachers can collaborate with staff outside the cooperative teaching model in many ways. Through cooperative planning and collaboration, they can share information about students' learning strengths and weaknesses and possible teaching strategies and accommodations that might prove beneficial. A peer coaching technique might be used to share a teaching routine that the content teacher could implement in the class, or the special education teacher might do some demonstration teaching on a one-time or short-term basis to help the content teacher implement a new teaching technique in a class (Robinson \& Knackendoffel, in prep.). 


\section{Cooperative Teaching}

A special education teacher may be in a situation in which a large number of "high-need" students are enrolled in a class required for graduation. These two factors - the sheer number of students and their intense levels of needed educational services-may necessitate moving beyond collaborative consultation to a cooperative teaching model. Cooperative teaching (or coteaching) is an approach in which general and special educators teach students jointly in educationally integrated settings (Bauwens, Hourcade, \& Friend, 1989; Robinson \& Knackendoffel, in prep.).

Cooperative teaching is a direct and complementary outgrowth of the collaborative consultation model described by Idol, Paolucci-Whitcomb, and Nevin (1986). Specifically, in cooperative teaching arrangements two or more educators (for our purpose, a general education teacher and a special education teacher) are present simultaneously in the content class and maintain joint responsibility for the instruction in the general education classroom. They have mutual ownership, pooled resources, and joint accountability. This approach has gained considerable popularity at the secondary level because it capitalizes on the specific and unique skills each professional brings to the classroom. General education teachers, as a group, are knowledgeable about curriculum and appropriate scope and sequence in traditional academic areas. They also know how to manage large groups of students for instruction. Special educators traditionally have been trained to target areas of difficulty within a curriculum and can analyze and adapt materials and strategies for instruction. Individualized instruction is almost second nature to most special educators.

Thus, the two professionals working together can bring a wealth of skills to the cooperative teaching arrangement. Each teacher's level of participation varies depending on the individual teachers' strengths and preferences, content being taught, and composition of students in the class.

Several different options are possible when arranging cooperative teaching. Three that will be discussed here are (a) team teaching, (b) supplemental learning activities, and (c) complementary instruction. Any of these approaches can be combined in a given situation and, therefore, should not be seen as mutually exclusive. Two teachers may start out using the supplemental learning activities model but after time feel comfortable enough with one another to engage in team teaching. Likewise, while team teaching, a teacher may discover the need to move into complementary instruction for a portion of the class period. Based on the skills and preferred styles of the teachers, they need to discover what will best accommodate the teaming situation. What works with one teacher with one group of students doesn't necessarily work in another classroom or with another teacher. Successful teaming means personalizing the approach for each situation.

\section{Team Teaching}

Team teaching involves both the general educator and the special educator planning and teaching the academic subject content jointly to all students in the class. At various times, one teacher might assume primary responsibility for specific types of instruction or portions of the curriculum. For example, during a social science class, the special educator might introduce the lesson using an advance organizer and preteach key terms that will be used in the lecture and reading using direct instruction procedures. This might be followed by the general education teacher presenting a lesson on the causes of the Civil War.

When team teaching both teachers might share teaching responsibilities, shadow the other's teaching, or do a combination of both. Team teaching can be carried out in a number of ways. In practice, one teacher might be talking while the other is providing examples using an overhead transparency or chalkboard, or when preparing for instruction one teacher prepares the lecture while the other prepares study guides or cognitive maps to guide the instruction. Another example of team teaching is teachers' taking turns with lesson preparation to change the pacing and focus while the other monitors. Finally, one teacher can lecture to the class while the other provides examples to help clarify key points. Team teaching should not be confused with "turn-teaching" (I teach, you teach-back-and-forth). Team teaching can be described more accurately as teaching in concert with one another. It is more than merely going back and forth between two instructors who teach in the same classroom.

For team teaching to be most effective, thoughtful planning and coordination are important. When mapping out the lesson, the teachers can discuss places in the lesson where one teacher will model while the other speaks, or where one teacher will demonstrate while the other explains. Much of effective team teaching is also spontaneous and intuitive. If one teacher can try to see and hear the other teacher through the eyes and ears of the students, he or she might be able to determine if the pace is appropriate, when clarification is needed, or if recall can be facilitated by using a pause/discuss procedure (Ruhl, Hughes, \& Schloss, 1987). Team teaching may be especially applicable at the secondary level when the LD specialist is certified in a specific content area where the cooperative teaching is occurring.

\section{Supplemental Learning Activities}

Using the supplemental learning activities approach to 
cooperative teaching, general and special educators plan and deliver instruction together in the general education classroom. Under this arrangement the content teacher maintains primary responsibility for delivering the essential content, while the special education teacher is responsible for developing and implementing supplementary learning activities. These supplementary learning activities might include things such as cooperative learning (Johnson \& Johnson, 1986; Rottier \& Ogan, 1991; Slavin, 1986), peer tutoring (Jenkins \& Jenkins, 1981; Miller, Kohler, Ezell, Hoel, \& Strain, 1993), the pause/discuss procedure activity (Ruhl, Hughes, \& Schloss, 1987), role plays, simulations, partner reading, numbered heads, learning games, center work, debates, and so on.

An example of a supplementary learning activity arrangement might look something like this. During cooperative planning two teachers agree that a certain skill in an English class should be taught to all students in their shared class. Together they determine which supplementary learning activities would be most appropriate for reinforcing the skill (e.g., peer tutoring, projects, cooperative learning). The English teacher then would introduce the content initially and the LD specialist would be responsible for the development and implementation of whatever supportive learning activities the two had agreed upon to reinforce the new content.

\section{Complementary Instruction}

One final example of a cooperative teaching structure that is particularly well suited for the secondary level is complementary instruction. Using this approach, the content teacher maintains primary responsibility for teaching the specific academic content while the special education teacher teaches the critical academic survival or learning skills necessary to acquire the content. These survival skills might include things such as notetaking, paraphrasing, outlining, memorizing, listening, and a host of learning strategies such as test taking, word identification, error monitoring, and so on.

Academic survival skills can be addressed with the entire class at the beginning of a lesson, throughout the presentation, or in a review at the conclusion of the lesson. If any students do not need this specialized complementary instruction, the content teacher could assign and monitor enrichment activities based on previously covered material while the remaining students are involved in the survival skills instruction. Besides deciding when during the period to instruct in survival skills, another consideration is how often? A teacher may prefer to provide academic survival skills instruction on a regularly scheduled basis (such as once a week, 3 days per week, or other schedule).

Complementary instruction differs from the supplemental learning activities approach in that in complementary instruction the content teacher takes responsibility for delivering the academic content (the "what" of learning) while the LD specialist in this case teaches the students "how to learn" (academic survival skills) or acquire the content. In contrast, with the supplemental learning activities approach the content teacher introduces the essential academic content of the lesson while the LD specialist develops supplementary activities to enrich the academic content, thereby aiding in the students' learning and retention of the information.

Complementary instruction traditionally has occurred in support class settings where the students with learning disabilities were pulled out for specialized instruction. One of the drawbacks of delivering specialized instruction in segregated special education settings is that students typically don't generalize newly acquired skills to the content class without deliberate efforts to teach for generalization. The benefit to the complementary instruction approach is that students are more likely to use the academic survival skills immediately and therefore see the need and benefit in learning the skills, thus increasing the motivation to learn and the probability of generalization.

Part of the appeal of cooperative teaching, besides the generalization issue, is that all students are more likely to receive appropriate educational programs, regardless of whether they meet the strict identification guidelines for a documented learning disability. Through cooperative teaching more individualized teaching becomes possible and each teacher is able to capitalize on his or her unique skills. Teachers using this arrangement have the added benefit of coaching one another so they begin to share the same language and a body of teaching information that will benefit them in a wide variety of teaching situations. Through cooperative teaching educators are able to minimize the need for more traditional special education pull-out programs when students have diagnosed learning disabilities (Bauwens, Hourcade, \& Friend, 1989).

\section{Coaching}

One of the major misconceptions about teaching is that it is a relatively commonplace, easy-to-learn profession. In truth, planning for and carrying out instruction involves complex cognitive processes. Research shows that most teacher planning and decision making are on-line and spontaneous (Borko, Livingston, \& Shavelson, 1990). Further, teachers tend to think in terms of activities, not objectives. To assist teachers in planning and adapting instruction for adolescents with learning disabilities, special educators have to understand the dynamics of this "on-the-spot" decision making. For most of us trained in special education, this represents a radical shift from the traditional short- and long-term objective model in which instructional planning is based on first specifying the objectives and then choosing carefully 
sequenced learning activities to meet these objectives.

This new body of research has clear implications for communication between special and general educators. Much of the emphasis has to be on assisting teachers with on-the-spot decisions regarding students with learning problems in the general education classroom. Communication has to be rooted in concrete images of more effective instructional practice - not so much in words as in concrete images (Gersten, 1990).

Aspects of the coaching model articulated by Joyce and Showers (1983) seem to be an excellent means of sharing this type of concrete, expert knowledge. Coaching is the process of giving teachers structured feedback about the instructional skills they used in a particular lesson (Cummings, 1985). Although some (e.g., Garmston, 1987) have made distinctions between different types of coaching (e.g., technical, collegial, and challenge coaching), the basic idea in a peer coaching situation is that teachers are engaged in instructing, training, and tutoring one another. Coaching typically involves numerous observations of classroom practice, followed by discussions (largely informal) of the observations. Often the person involved in coaching-in this case, the LD specialist-will model a teaching technique or strategy. Observations often center on a specific instructional practice with which the teacher is experimenting (Showers, 1985).

By its very nature coaching is concrete. It is rooted in the world of the classroom and the language of instruction, not the language of behavior management and psychopathology (Gersten, 1990). Those involved in coaching can model not only instructional techniques but also procedures for checking for student understanding during the lesson. Coaches actually can model on-the-spot decision making. Sharing effective instructional methodologies is a process rather than a single act or event wherein a person merely tells another about a given teaching routine.

A major goal of collaboration with general education teachers should be to increase their expertise in working with students who have special learning needs in their classes. Coaching seems to have great potential for accomplishing this goal. When special educators share an instructional technique or strategy with a collaborating teacher, they must consider the complexity of the change process. To illustrate this point, consider when teachers have learned alternative teaching strategies through traditional theory/ demonstration/practice staff development training designs. In studies in which half of the participants were assigned to "coaching" follow-up training programs while the remaining teachers were left on their own to implement the new teaching strategy, the coached teachers exceeded their uncoached comparison group in implementation of the new strategies by a dramatic margin. About $80 \%$ of the coached teachers transferred the new strategies to their active teaching repertoires, compared with about $10 \%$ of the uncoached teachers (Showers, 1990).

If colleagues are to adopt a new teaching strategy as part of their teaching repertoire, they must plan deliberately for this change process. Robinson and Knackendoffel (in prep.) suggested several key steps in the coaching process:

Step 1: Set stage for collaboration, and introduce teaching routine

Step 2: Gain commitment to listen to teaching routine

Step 3: Describe teaching routine

Step 4: Model teaching routine

Step 5: Gain commitment to try teaching routine

Step 6: Offer assistance for initiating the routine

Step 7: Collaborate on effectiveness of routine in content class

Step 8: Provide for maintenance and adoption of teaching routine

Systematic implementation of this process is designed to increase the likelihood that the new teaching routine will be adopted.

In many ways the process is analogous to an apprenticeship. Suggestions to colleagues should be clear, and they must be achievable (Rosenholtz, 1989). Often, in the role as the coach, modeling or demonstrating the alternative instructional strategy is appropriate. Quickly the learning teacher takes an active role in using the new technique while the coach assumes the role of facilitator, encouraging the teacher in implementing the teaching routine.

\section{DEFINING ROLES AND RESPONSIBILITIES}

Particularly in the infancy stage of setting up cooperative teaching programs, the special education teacher should choose to work with a person who has a similar philosophical orientation and teaching style. Down the road, with some experience and confidence, the special educator might be more adventuresome or take on the challenge of working with a teacher whose approach to teaching is much at variance.

The process should begin by selecting basic skill classes (e.g., English, Math) or required classes at the secondary level, such as American history, that all students must take to graduate. By choosing these classes, teachers will be able to reach the maximum number of targeted students. From the pool of teachers responsible for these classes, the choices can be narrowed by first thinking about the teachers who may be most open to collaboration. Teachers may be tempted to select teachers they think could benefit most from having a special education teacher in their classes (marginal teachers who are instructionally weak, teachers 
who are known for teaching only one way, or classes where LD students historically have had difficulty). Although the motive behind this plan may be good, the teacher runs the risk of failure. A better approach is to target strong teachers initially to engineer successful collaboration.

Once the class(es) and teachers targeted for the collaborative teaching model have been decided, the next step is to schedule students into the classes. When collaborative classes exist in a school, the temptation always is to overload these classes with high-risk students. Besides scheduling into the class students with identified learning disabilities, other students who may not have qualified for special education but nevertheless could benefit from this type of program may be placed there. Certainly this practice is well intentioned, but care must be taken not to upset the applecart. To maintain a balance and prevent the class from becoming a dumping ground or viewed as a special education class, a rule of thumb is to allow no more than $30 \%-50 \%$ of the composition to be learners with special needs (Nowacek, 1992). This includes the students identified for special education as well as others who have special learning needs.

Hand-scheduling is a must during this phase of preparation. It can be one of the most frustrating and difficult hurdles to overcome. Even though the class will have two teachers, collaborative classes should not be larger than average. In addition to scheduling students on the special educator's caseload into the collaborative class(es), these students also will have to be scheduled for resource or support classes when needed. Unfortunately, the more the teacher is involved in collaborative teaching, the less time is available for resource support, which presents yet another scheduling problem. With fewer options for scheduling students into the resource program, resource periods will become larger in terms of total number of students. This is not necessarily a negative factor, because teachers may discover that they can use the time in the support class more efficiently, as they will be working with these students throughout the day in their collaborative classes.

Also, teachers may find they can work with the other special education teachers in the school to staff a resource room more consistently throughout the day (i.e., instead of two special education teachers being scheduled in the resource room during one period, one of the teachers might run the support class and provide direct service while the other is involved in cooperative teaching or collaborative teaming activities)

Sometime before the first day of class, the teacher should meet with the collaborating team members to discuss and plan the program. Some teachers spend up to a year preparing to work as a team and creating collaborative teaching structures. Others seem to be thrown together almost hap- hazardly and meet only a few times before starting the program. Regardless of the preparation time involved, teachers often feel at a loss about what to discuss about their individual roles in a collaborative class. When faced with the prospect of collaborative teaching, they might ask, "What will I do for a whole period in another teacher's classroom?" "What type of assistance can I provide, and how will I be received by the teacher and the students?"

First, teachers should throw out any preconceived notions about how things should be done in a collaborative class. The format of each collaborative class will be the result of the interaction between the collaborating teachers. Many teachers involved in collaborative teaching describe their role as "evolving" (Nowacek, 1992). They learn to "read" their team member by standing back and observing, waiting to see what they can do rather than coming in with their role and responsibilities chiseled in stone. Teachers must be willing to play the role of an aide at times, particularly in the beginning. To establish their contribution and role in the classroom, they might reflect on the needs and how they can best fit into those areas. Initially this may mean running off papers or typing a test. In the beginning suggestions should be offered tactfully. With time, the partner likely will not wait for suggestions but, instead, will actually solicit opinions and feedback from the partner-a perfect opportunity for coaching. This level of trust and respect does not happen overnight. Secondary teachers have a long history of working solo. Therefore, establishing a "comfort zone" will take time.

Even though the role of the teachers involved in collaborative teaching is an evolving one, that is not to say that time spent discussing possible roles and parameters of the program is not time well spent. This discussion might begin with each teacher answering these questions independently:

- How do you envision your role and the partner's role in the collaborative teaching model?

- What are the possible advantages of teaming?

- What are your fears?

After considering these questions, the answers should be discussed with one another. This will help highlight areas of agreement and difference so the process of negotiation of roles and responsibilities can begin and together the teachers will truly share the territory of the classroom. A format similar to the one provided in Figure 3 might be used to help structure and guide this process.

Another way a teacher might prepare for the collaborative class is to conduct a setting demands interview with the classroom teacher prior to working together and arrange to observe the class on one or more occasions. Formats suggested in Assessing Classroom Demands (Knackendoffel \& 
How do I envision my role in this collaborative situation? How do I envision my partner's role?

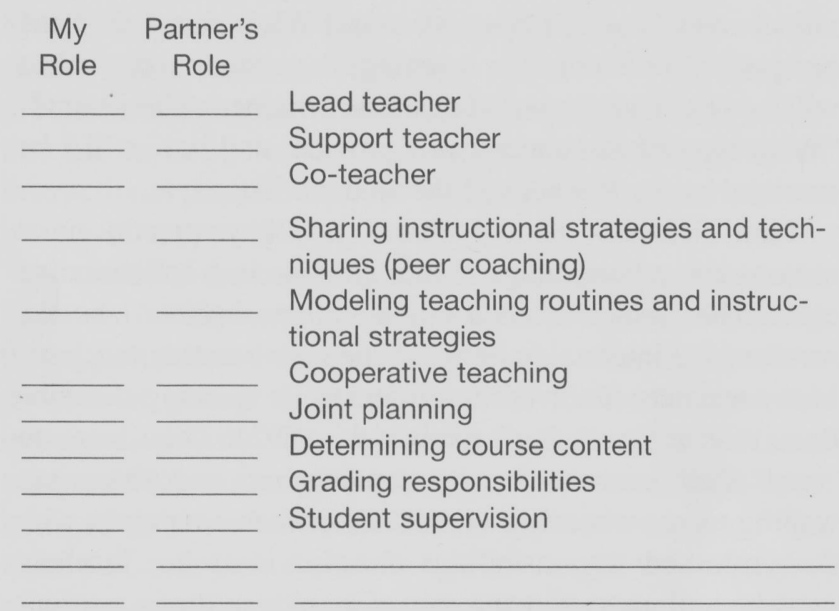

\section{RESPONSIBILITIES/ASSISTANCE:}

\section{My Partner's}

Role Role

\section{Modifying tests}

Developing alternative assessments

Developing student notes

Monitoring and assisting students during instruction and seatwork activities

Developing study guides and/or review sheets and exercise

Adapting the textbook and/or other readings

Developing alternative learning arrangements or groupings (peer tutors, coop. learning)

Adapting assignments

Developing a modified grading system Classroom management

What are the possible advantages of us teaming together?
Why would someone want me as a partner? (your strengths) Instruction:

Personal:

Organization:

Misc.

Issues to discuss before entering into collaborative teaching arrangements:

- What will each teacher's responsibility be for students with special needs (instruction, seating, grouping, grading, assignments, etc.)?

- Grading (philosophy, who will do it, recording in grade book, modifications in grading system)

- Who will present the content?

- How will the planning take place?

- How will we handle various task completion issues (absences, missing homework, etc.)?

- How will we present our model to parents and students (i.e., Why are two teachers in this classroom?)?

- Discuss and agree on classroom routines.

- What type of behavior management system will be in place, and what will each of our roles be?

How will you evaluate and revise your model? (Periodically both teachers should respond to these questions and discuss.)

What is going well?

What would you change? 
Robinson, in prep.) and The Instructional Environment Scale (Ysseldyke \& Christenson, 1993) might provide a structure for determining the demands of the content class. Teachers will want to gather information regarding the various teaching methods used (e.g., lecture, small-group instruction, cooperative learning), how students are evaluated, what type of tests are given, and what written products are required of the students, collect information about the textbook suitability for students who are reading below grade level, and determine the teacher's expectations regarding classroom management.

The special educator can learn more specific information by requesting certain materials (e.g., textbook, graded tests, and homework) to study after the interview is completed. For example, looking over a graded test may reveal how the teacher scores an essay question when a student knows the basic concept but has poor writing skills. This type of information usually is not extrapolated during the interview.

During one or more observations in the classroom, the special educator can observe the general class environment, witness the instructional presentation in action, observe student behaviors such as on- and off-task during class, and reflect on teacher behaviors regarding classroom management, provisions for feedback and reinforcement, and a host of other interactions between teachers and students. After the observation(s), interview, and examination of materials, the setting demands information can be compiled, and the special educator should set up a time to meet with the content teacher to share the results. Initially the purpose of this meeting might be to have the content teacher confirm or dispute the special educator's findings so inaccurate information can be corrected.

If the summary depicts an accurate picture of the setting demands, the utility of this task becomes readily apparent. Many teachers report that the setting demands interview opens the door for discussions between the content teacher and the special educator about teaching methods, test modifications, adapting materials, and so on (Knackendoffel, 1989). It can be used as a springboard for future discussions about material modification and instructional grouping arrangements. This information also can help teachers better prepare students for meeting the demands of specific content classes.

\section{UNDERSTANDING AND RESOLVING CONFLICT}

One area that often causes anxiety is how to avoid conflict in the collaborative role. Traditionally, school professionals have disliked and avoided conflict. This was particularly the case when school culture emphasized isolation rather than collaboration. Increasingly, staff members in today's schools are expected to work together, which is bound to result in conflict sooner or later. Simply stated, conflict is any situation in which two or more people disagree about something. Conflict is unavoidable. Differences in opinions, values, and needs are part of our daily existence. Conflict is neither good nor bad (Schmuck, Runkel, Arends, \& Arends, 1977). The judgment one makes about conflict is what determines whether it is perceived as having positive or negative outcomes.

As a response, one might remember the old saying, "When life gives you lemons, make lemonade!" Instead of wasting an inordinate amount of energy on avoiding conflict, the teacher might think of some of the potential positive outcomes that can emerge. Conflict may result in higher-quality decisions, as well as the involved parties' taking greater ownership in decisions. Another value of conflict is that it can prevent stagnation, stimulate interest and curiosity, and foster creativity (Bolton, 1979). Finally, more open, trusting relationships may emerge as a result of conflict. Confrontation is a necessary ingredient of organizational renewal.

When the causes of conflict and influencing factors are understood, teachers are better able to identify and manage conflict situations that arise in teaming efforts. The conflict experienced in the teacher's role is influenced significantly by the school's organization and administration. Factors such as the principal's leadership style and communication among various components of the organization affect the likelihood of conflict.

Personal characteristics of one's colleagues also can be a source of conflict. When people are in difficult conflict situations, many times they display a variety of negative behaviors such as verbal or physical aggression, reduced conversation, or walking away.

\section{Conflict Management Styles}

Friend and Cook (1992) maintain that most people have a preferred conflict management style. Table 1 identifies five conflict management styles and the characteristics of each style. None of these styles is entirely positive or negative. Depending on the situation in which it is used, each has both merits and drawbacks.

\section{Competitive Style}

People who use the competitive style try to overpower the other person who is standing in their way. They focus on "winning" at the expense of the relationship. This style often is associated with power. At times a competitive style might be appropriate (e.g., when ethical issues are at stake). Usually, however, this style can seriously damage the collaborative relationship. This approach should be reserved for issues in which a person believes with the heart and soul. 


\section{TABLE 1}

\section{STYLES OF MANAGING CONFLICT AND THEIR CHARACTERISTICS}

\begin{tabular}{ll} 
Style & What They Do \\
\hline Competitive & $\begin{array}{l}\text { pursue their goals } \\
\text { try to get their way or win their position } \\
\text { press their points by showing the other person the logic and benefits of their position } \\
\text { assert their wishes }\end{array}$
\end{tabular}

Avoidance

Accommodating

Compromising

Collaborating sometimes let others solve the problem

try to avoid tension and unpleasantness

are likely to postpone so they have time to think over an issue

avoid controversial positions

focus on areas of agreement rather than issues that separate

try to soothe feelings and preserve the relationship

sometimes are willing to sacrifice their own wishes for the wishes of others

work hard not to hurt others' feelings

try to find a compromise

are willing to give up some points in exchange for others

are likely to propose a middle ground

try to reach a fair agreement in which both parties gain and losses are equalized

attempt to deal with the concerns of all parties involved

seek the help of others when working out a solution

attempt to get all concerns and issues immediately out in the open

share their ideas and also ask others for their ideas

deal with problems head on

attempt to work through differences

\section{Avoidance Style}

Individuals who use avoidance as a conflict management style turn away from conflict. On the outside they may give the impression that everything is fine, but just beneath the surface tension is building. Maybe a person refuses to discuss an issue or a group consciously avoids an underlying issue because it is "too hot to handle." In some situations this may be an appropriate response. When emotions are running high, the teacher may think it best to let people cool off before addressing the conflict. Avoidance also might be an appropriate strategy if time is lacking to address the problem. Or the issue may be inconsequential and not worth discussing. The danger with avoidance is that the issue sometimes is important and differences of opinion should be discussed and resolved. By avoiding the situation, the problem might actually worsen.

\section{Accommodating Style}

The accommodating person would rather give in than face a conflict situation. Many teachers of LD adolescents have operated with this style for years because they want to preserve positive relationships with colleagues. This might be an appropriate tactic if the issue is relatively unimportant, because the relationship certainly is an important consideration in successful collaboration. After time, however, this teacher may feel that he or she is always the one who is making concessions and eventually may begin to feel that others are taking advantage of him or her. This can damage the relationship in the long run. The bottom line is that an accommodating style is a useful tactic to explore for people who have a tendency to try to win every battle. It is inappropriate for those who feel resentful that colleagues don't respect their opinions or generally take advantage of their 
accommodating style.

\section{Compromising Style}

Some degree of negotiation will be necessary to function within a collaborative environment. Somewhere along the road, teachers may develop the notion that negotiation means compromise ("I give up something; you give up something"). This may result in a solution that is acceptable to all but that does not exactly meet the needs of anyone. Using a compromising style in conflict management is expedient and therefore may be called for when there is limited time to resolve the conflict. Compromise can have drawbacks if two competitive individuals, when in a conflict situation, decide to compromise. They may feel dissatisfied and conflict may surface at a later time. Friend and Cook (1992) described compromise as being more assertive and cooperative than the avoiding style but less so than the collaborating style.

\section{Collaborative Style}

A collaborative approach to conflict calls for high degrees of both assertiveness and cooperativeness. It often involves developing a completely new alternative to the conflict situation. It is a time-consuming process and can only happen when professionals learn about and come to trust one another. Therefore, like the other styles discussed, it may not be the most appropriate choice, or even an option, in all conflict situations.

\section{Suggestions for Resolving Conflict}

No simple formula can be applied to every conflict resolution situation encountered in collaboration. Probably the best overall technique is problem solving. Conflict management is merely a special example of the problem-solving process. The steps in problem-solving are as follows:

1. Identify and define the problem (conflict) using active listening to reduce anger or defensiveness in the other person.

2. Don't rush; take time to understand the other person's point of view.

3. Generate several alternative solutions, taking care not to evaluate until all possibilities are out on the table.

4. Evaluate the alternative solutions by examining flaws, barriers, difficulties in implementing, and so on. Make a decision.

5. Make a mutual commitment to one solution. Don't persuade or push a solution. If it is not freely chosen, it is unlikely to be carried out.
Clear communication is essential. Listeners should concentrate on what the speaker is saying and how it is being said. They need to understand the point of view of the person with whom they have a conflict. This will help in constructively resolving it. Paraphrasing important concepts helps clarify areas of uncertainty, and emphasizes them, and it lets the other person know that he or she is understood. Active listening can go a long way in diffusing some of the tension in a conflict situation.

Negotiation is another useful technique. Even though most people do not view themselves as negotiators, they probably engage in informal negotiations every day. During conflict situations the negotiation strategies have to be more conscious and deliberate. In their book Getting to Yes, Fisher and Ury (1981) identified four principles of negotiation that can be used in conflict situations.

1. Separate the person from the problem. Look beyond the surface of the conflict, and respond to the people issues. Preserving the relationship should be a top priority. Try to understand the other person's thinking by putting yourself in his or her shoes, and then try to make your proposals consistent with the other person's values.

2. Focus on interests, not positions. Behind opposing positions lie shared and compatible interests as well as the conflicting one. Identify interests by addressing the following:

a. Ask why the other person wants what he or she wants.

b. Ask "why not?" Think about his or her choice. Why doesn't he or she like your position? What interests stand in the way?

c. Realize that each side has multiple interests. Look for compatible interests when searching for solutions.

d. Recognize that the most powerful interests are basic human needs. Don't overlook the obvious (security, sense of belonging, recognition, control over one's life).

3. Once interests have been identified, invent options for mutual gain. Four obstacles that inhibit the generation of multiple options are:

a. Premature judgment

b. Searching for a single answer

c. The assumption of a fixed pie (either/or)

d. Thinking that "solving their problem is their problem"

Invent creative options by:

- separating the act of inventing options from the 
act of judging them

- developing many options

- searching for mutual gain (identifying shared interests)

4. Insist on using objective criteria to evaluate your decision. The key here is using fair standards.

\section{MANAGING RESISTANCE}

Resistance can be even more troubling than out-and-out conflict. With conflict situations, the disagreement is apparent, and one can choose whether to resolve it or not. Resistance is much more elusive. The words, actions, and even inaction of colleagues may be interpreted in many different ways.

\section{Why People Resist}

Friend and Cook (1992) identified many causes for resistance. People often resist because of how they perceive the change or its outcomes. Change requires new ways of thinking. Doing so is difficult and induces feelings of awkwardness (Fullan, 1985). Basically, it evokes fear of the unknown. The perceptions actually may be inaccurate or the person may be reacting to partial information. Generally, the more ambiguity, the more likely the resistance.

Colleagues also are likely to resist because of the personal impact of the change. For example, if the proposed change will alter their professional functioning or role, they may be afraid of failing. They may not feel comfortable in learning new skills or practices. These feelings of insecurity can be exacerbated when people think they lack the training or experience to carry out the new role. If the proposed change involves working with others and the person is accustomed to working more autonomously, that person's autonomy may be threatened.

Sometimes people resist an idea based on the person who is suggesting it rather than any specific objection to the idea itself. They may have a different personal style or may not respect the individual because of past experiences. The resistance even could be based on the person's being new or not having established a trusting relationship with the person proposing the change. Imagine the potential for resistance evoked by a new staff member approaching a veteran teacher about co-teaching a class together.

Finally, sometimes people resist change for change's sake. They become comfortable in their role or wish to maintain the status quo. As a rule, organizations resist any type of change. Schools, like other organizations, seek to maintain some level of homeostasis.
Because resistance is much more elusive than conflict, how can people recognize it? Friend and Cook (1992) pointed out several ways in which resistance may be manifested. One particularly disturbing type of resistance is when people seem to support one's ideas by their verbal and nonverbal responses but then choose not to act on them. People often choose this response because agreeing overtly with the ideas and subsequently not acting upon them is easier than openly disagreeing with the person and possibly initiating conflict, or at least a lengthy discussion.

Another subtle type of resistance is when the other party procrastinates in one way or another-slow to implement the intervention, schedule a meeting, and so on. Certainly these delays can be legitimate, but if a pattern of delays emerges, it is likely an indicator of resistance.

At times people show their resistance by making comments such as:

- We've always done it this way.

- This is just the latest educational fad. I'm sure we'll be on to something else tomorrow.

- I don't see anything wrong with the way we're doing things now.

They are saying that they prefer to rely on past practice and are generally suspicious of change. A related approach is when the person refuses to take responsibility for rejecting the change. Instead, the colleague may defer to another group (e.g., parents, other teachers), an authority figure such as an administrator, or cite a policy or law that would prohibit the idea. Comments may include:

- The administration in this district has never been supportive of this type of service delivery.

- I think you'll be facing an uphill battle with most of the parents.

- Even if I agree, you'll never get the other teachers to go along with this idea.

Finally, one of the clearest indicators of resistance is when the person simply refuses an offer to participate. Of the indicators of resistance discussed thus far, this might be the preferred one, as it is not subtle and clearly conveys resistance. Knowing that resistance exists, the teacher can either acknowledge the appropriateness of the resistance or use strategies to overcome the resistance (discussed later).

\section{When to Address Resistance}

When sensing resistance, the teacher must decide whether to address it or not. Friend and Cook (1992) suggested that the person examine if the resistance is appropriate, whether the effort to address it is warranted, and others' commitment to change. 
When encountering resistance, the place to start is to consider the situation from the other person's point of view. Does the change place undue hardship on the person? Looking at the resistance through the eyes of the other party better prepares one to address the obstacles that stand in the way of implementation.

Another consideration is whether addressing the resistance is warranted. Sometimes the best response to resistance may be not to respond at all. In some situations the effort simply may not be worth it. For example, a teacher may lack the administrative backing to pursue an idea with a resistant staff. Or the teacher may be aware that personnel changes will be taking place at the end of the year, which will make the struggle a moot point.

Finally, the teacher should assess the other person's commitment to change. This will help gauge one's own commitment to change. Too, people are less likely to change if emotions are running high. Sometimes, letting an idea simmer in others' minds before readdressing with a highly resistant staff can be advantageous.

\section{Strategies for Overcoming Resistance}

Persuasion is one strategy that is available. Several resistance management strategies may be beneficial.

1. Provide incentives/recognition. Adults, not unlike students, have different needs at different times. If they are to be influenced their emotional and physical needs have to be met (DeBoer, 1986). The idea here is to reward the person for participating. This might include things that would reduce workloads, such as assistance with classroom chores (e.g., test grading, preparing study guides). All of us appreciate recognition. Exemplary programs can become model classrooms. for others to observe.

2. Provide modeling/observation time. If the colleague can observe implementation of a new instructional procedure or visit another school where a similar program is being carried out, perhaps he or she will be more receptive to the change. Providing this opportunity to observe someone else removes some of the fear associated with the unknown. For example, a good way to alleviate a teacher's fear about a student who is to be mainstreamed into the class is to arrange an informal meeting with another teacher who has worked with the student successfully.

3. Anchor change in familiarity. People like to feel comfortable, and change generally makes us feel uncomfortable. Therefore, the change should be tied to others' knowledge and experience. Each of us has a certain tolerance for change. The key is to determine the other person's tolerance and propose ideas that fall within it. The information shared is not as important as how the information is perceived (Shelby, 1986). When proposing a new idea, frame the idea in familiar language, and ground the idea in the other person's value system. This requires some reflection before making the proposal so it can be "packaged" in a way that will make it acceptable to the other person.

4. Address others' needs. One approach that has proven effective when dealing with resistance is to identify the underlying needs of the other person and enable those needs to be addressed (Fisher \& Ury, 1981). Although we all have our own unique needs, teachers often have needs in common such as the need to feel control over the immediate work setting (e.g., classroom, caseload, schedule), a need to be appreciated and acknowledged for their efforts on behalf of students, and a need for a high degree of structure in their roles (Friend \& Cook, 1992). To the extent that teachers can relate their proposals to the needs of others, the greater is the chance it will be accepted.

5. Involve others in planning. Regardless of the nature and scope of the change, teachers will meet much less resistance if they include others early in the planning process (Johnson \& Johnson, 1987; Margolis \& McGettigan, 1988). This early involvement allows them to address concerns as they arise and provides the colleagues with a sense of ownership and a personal investment in making the plan successful.

6. Solicit feedback. Much of the resistance encountered in the collaborative role can be alleviated by simply asking for input from those involved. For example, if you are working with a content teacher on accommodations for a student with a learning disability in a social science class, you might gather information in a setting demands interview (discussed earlier in this chapter) to determine what approaches seem most suited to the class. Once these accommodations have been implemented, the two of you should meet to discuss whether these have been successful. The feedback should be used to alter the plan and make it more effective. Again, this type of approach helps participating teachers feel more involved in the plan and fulfills their need to be appreciated and acknowledged for their efforts on behalf of students (Margolis \& McGettigan, 1988).

7 Stress voluntariness when resistance is present. None of us likes to be told to do something whether we like it or not. When people sense they are being backed into a corner with few or no options, they are likely to dig in their heels and resist the proposed change. People like to have their input sought and feel their contribution is valued. When interacting with others concerning change, the teacher should convey clearly that they have a choice (West, Idol, \& Cannon, 1989). A general principle for addressing resistance is to respect the rights of others to object to change and to encourage them to discuss their points of view. 


\section{REFERENCES}

Bauwens, J., Hourcade, J. J., \& Friend, M. (1989). Cooperative teaching: A model for general and special education integration. Remedial and Special Education, 10(2), 17-22.

Bolton, R. (1979). People skills: How to assert yourself, listen to others, and resolve conflicts. New York: Simon \& Schuster.

Borko, H., Livingston, C., \& Shavelson, R. J. (1990). Teachers' thinking about instruction. Remedial and Special Education, 11(6), $40-49,53$.

Cummings, C. (1985). Peering in on peers: Coaching teachers. Edmonds, WA: Teaching, Inc.

Cummings, A. L., Murray, H. G., \& Martin, J. (1989). Protocol analysis of the social problem solving of teachers. American Educational Research Journal, 26, 25-43.

DeBoer, A. (1996). The art of consulting. Chicago: Arcturus Books.

Dettmer, P., Thurston, L. P., \& Dyck, N. (1993). Consultation, collaboration, and teamwork for students with special needs. Boston: Allyn \& Bacon.

Fisher, R., \& Ury, W. (1981). Getting to yes. Boston: Houghton Mifflin.

Friend, M., \& Cook, L. (1992). Interactions: Collaboration skills for school professionals. New York: Longman.

Fullan, M. (1982). The meaning of educational change. New York: Teachers College Press.

Fullan, M. (1985). Change processes and strategies at the local level. Elementary School Journal, 85(3), 391-420.

Garmston, R. J. (1987). How administrators support peer coaching. Educational Leadership, 44(5), 18-26.

Gersten, R. (1990). Enemies real and imagined: Implications of "teachers' thinking about instruction" for collaboration between special and general education. Remedial and Special Education, 11(6), 50-53.

Harris, K. C., Harvey, P., Garcia, L., Innes, D., Lynn, P., Munoz, D., Sexton, K., \& Stoica, R. (1987). Meeting the needs of special high school students in regular education classrooms. Teacher Education and Special Education, 10(4), 143-152.

Idol, L., Paolucci-Whitcomb, P., \& Nevin, A. (1986). Collaborative consultation. Austin, TX: Pro-Ed.

Jenkins, J. R., \& Jenkins, L. M. (1981). Cross age and peer tutoring: Help for children with learning problems. Reston, VA: Council for Exceptional Children.

Johnson, D. W., \& Johnson, F. P., (1987). Joining together: Group theory and group skills (3d ed.). Englewood Cliffs, NJ: Prentice Hall.

Johnson, D. W., \& Johnson, R. T. (1986). Mainstreaming and cooperative learning strategies. Exceptional Children, 52, 553-561.

Joyce, B., with Bennett, B., \& Rolheiser-Bennett, C. (1990). The selfeducating teacher: Empowering teachers through research. In B. Joyce (Ed.), Changing school culture through staff development (pp. 26-40). Alexandria, VA: Association for Supervision and Curriculum Development.

Joyce, B., \& Showers, B. (1983). Power in staff development through research on training. Alexandria, VA: Association for Supervision and Curriculum Development.

Knackendoffel, E. A. (1989). Development and validation of a set of teaming strategies for enhancing collaboration between secondary resource and content teachers. Unpublished doctoral dissertation, University of Kansas, Lawrence.

Knackendoffel, E. A., \& Robinson, S. M. (in prep.). Assessing classroom demands. Lawrence, KS: Edge Enterprises.

Knackendoffel, E. A., Robinson, S. M., Deshler, D. D., \& Schumaker, J. B. (1992). Collaborative problem solving: A step-by-step guide to creating educational solutions. Lawrence, KS: Edge Enterprises.

Margolis, H., \& McGettigan, J. (1988). Managing resistance to instructional modifications in mainstreamed environments. Remedial and Special Education, 9(4), 15-21.

Miller, L. J., Kohler, F. W., Ezell, H., Hoel, K., \& Strain, P. S. (1993). Winning with peer tutoring: A teachers' guide. Preventing School Failure, 37(3), 14-18.

Nowacek, E. J. (1992). Professionals talk about teaching together: Interviews with five collaborating teachers. Intervention in School and Clinic, 27(5), 262-276.

Rosenholtz, S. J. (1989). Workplace conditions that affect teacher quality and commitment: Implications for teacher induction programs Elementary School Journal, 89, 421-439.

Robinson, S. M., \& Knackendoffel, E. A. (in prep.). Developing collaborative programs: Promoting professional development and change. Lawrence, KS: Edge Enterprises.

Rottier, J., \& Ogan, B. J. (1991). Cooperative learning in middle-level schools. Washington, DC: National Education Association.

Ruhl, K. L., Hughes, C. A., \& Schloss, P. J. (1987). Using the pause procedure to enhance lecture recall. Teacher Education and Special Education, 10(1), 14-18.

Schmuck, R. A., Runkel, P. J., Arends, J. H., \& Arends, R. I. (1977). The second handbook of organization development in schools. Palo Alto, CA: Mayfield.

Shelby, A. N. (1986). The theoretical bases of persuasion: A critical introduction. Journal of Business Communication, 23, 5-27.

Showers, B. (1985). Teachers coaching teachers. Educational Leadership, 42(7), 43-48.

Showers, B. (1990). Aiming for superior classroom instruction for all children: A comprehensive staff development model. Remedial and Special Education, 11(3), 50-53.

Slavin, R. E. (1986). Using student teaming learning (3d ed.). Baltimore: Johns Hopkins University.

Warner, S. (1990). Research into practice: Collaboration and consultation in action. LD Forum, 16(2), 16-17.

West, J. F., Idol, L., \& Cannon, G. (1989). Collaboration in the schools. Austin, TX: Pro-Ed.

Ysseldyke, J. E., \& Christenson, S. L. (1993). The instructional environment system-II: A system to identify a student's instructional needs. Longmont, CO: Sopris West. 